\title{
Article
}

\section{Erratum: The tilting rate of the Milky Way's disc}

Earp, Samuel WF, Debattista, Victor P, Macciò, Andrea V and Cole, David R

Available at http://clok.uclan.ac.uk/25325/

Earp, Samuel WF, Debattista, Victor P ORCID: 0000-0001-7902-0116, Macciò, Andrea $V$ and Cole, David R (2019) Erratum: The tilting rate of the Milky Way's disc. Monthly Notices of the Royal Astronomical Society, 483 (2). p. 2100. ISSN 0035-8711

It is advisable to refer to the publisher's version if you intend to cite from the work. http://dx.doi.org/10.1093/mnras/sty3145

For more information about UCLan's research in this area go to http://www.uclan.ac.uk/researchgroups/ and search for <name of research Group>.

For information about Research generally at UCLan please go to http://www.uclan.ac.uk/research/

All outputs in CLoK are protected by Intellectual Property Rights law, including Copyright law. Copyright, IPR and Moral Rights for the works on this site are retained by the individual authors and/or other copyright owners. Terms and conditions for use of this material are defined in the policies page. 


\section{Erratum: The tilting rate of the Milky Way's disc}

\section{by Samuel W. F. Earp ${ }^{\oplus},{ }^{\star}$ Victor P. Debattista, ${ }^{1}$ Andrea V. Macciò ${ }^{\oplus 2,3}$ and David}

\section{R. Cole 4}

${ }^{1}$ Jeremiah Horrocks Institute, University of Central Lancashire, Preston, PR1 2HE, UK

${ }^{2}$ New York University Abu Dhabi, PO Box 129188, Saadiyat Island, Abu Dhabi, UAE

${ }^{3}$ Max-Planck-Insitute for Astronomy, Königstuhl 17, D-69117 Heidelberg, Germany

${ }^{4}$ Rudolf Peierls Centre for Theoretical Physics, University of Oxford, Keble Road, Oxford, OX1 3NP, UK

Key words: errata, addenda-Galaxy: disc-Galaxy: evolution-Galaxy: kinematics and dynamics - reference systems.

The paper 'Galaxy tilting in the era of Gaia', was published in MNRAS 4694095 (2017).

Fig. 4 showed the correlation between the tilting rate of the stellar disc and the distribution of local densities for spheres with radii 3,4,5 and $6 \mathrm{Mpc}$. The values for local density were incorrect by a factor of $4 / 3 \pi$, Fig. 4 shows the corrected values. This does not affect the correlations presented, or any of the conclusions in the original paper.

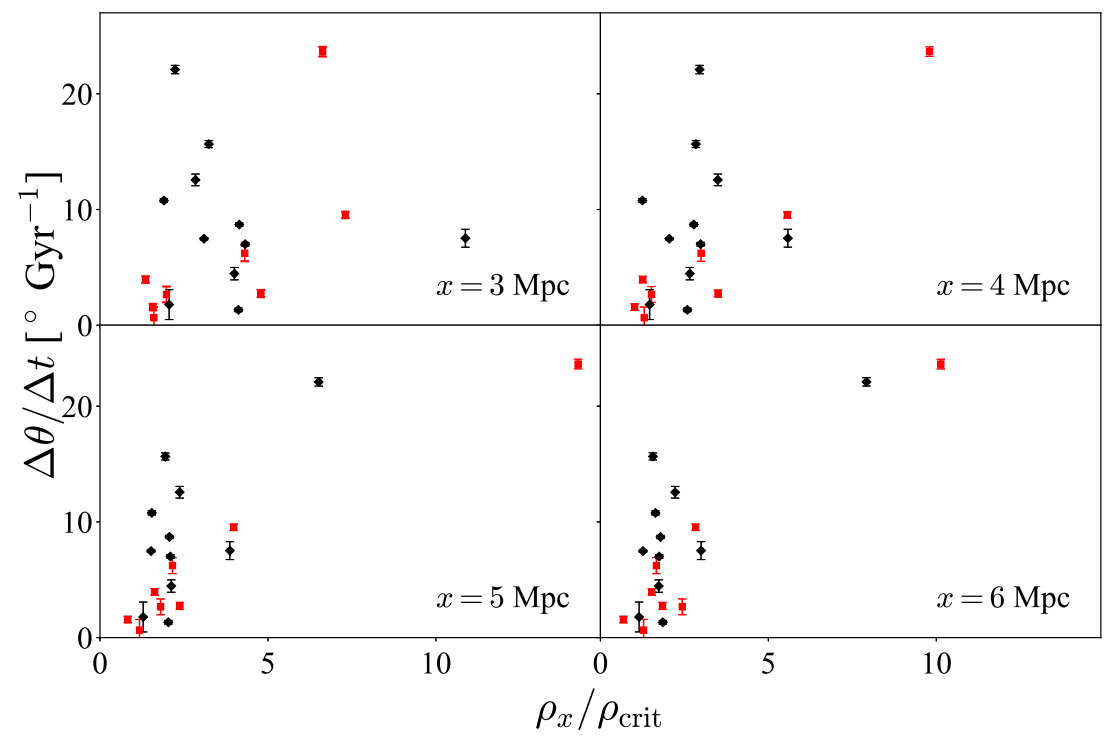

Figure 4. Tilting rate versus the local density within a sphere of radius $x$ at redshift $z=0$. In all panels, the (black) diamonds represent galaxies in subsample A with masses comparable to the MW,and the (red) squares show galaxies in subsample B with comparable mass and undergoing no interactions since $z=0.3$. We measure correlation coefficients for each panel $x=3,4,5$ and $6 \mathrm{Mpc}$ of $p=0.2,0.6,0.8$ and 0.8 , respectively, for all points, while for subsample B, we find $p$ values of $0.7,0.95,0.98$ and 0.97 , respectively.

This paper has been typeset from a $\mathrm{T}_{\mathrm{E}} \mathrm{X} / \mathrm{L} \mathrm{T} \mathrm{T}_{\mathrm{E}} \mathrm{X}$ file prepared by the author.

^E-mail: swfearp@gmail.com 